\title{
Simulador de relações públicas e gestão: inovação para o processo ensino- aprendizagem
}

\author{
PUBLIC RELATIONS AND MANAGEMENT SIMULATOR: INNOVATION FOR THE \\ TEACHING-LEARNING PROCESS
}

\section{Ana Cristina Costa Piletti Grohs ${ }^{1}$}

ORCID: https://orcid.org/0000-0001-9015-3702

(Universidade de Sorocaba, Curso de Relações Públicas, Sorocaba/SP, Brasil)

\section{Luis Fernando Martins Grohs ${ }^{2}$}

ORCID: https://orcid.org/0000-0002-6116-0089

(Universidade de Sorocaba, Sorocaba/SP, Brasil)

Recebido em 08/02/2019. Aprovado em 30/04/2019. 


\section{Resumo}

Iniciativas didáticas que articulem teoria e prática, valorizem o protagonismo do estudante e integrem diferentes conteúdos num contexto dinâmico, digital e interdisciplinar ainda são escassas na Educação Superior. Com o objetivo de fomentar a criação e o uso de metodologias ativas nos cursos de Relações Públicas, este texto apresenta alguns resultados de uma pesquisa multimétodos de doutorado no qual se elaborou e testou o Simulador de Relações Públicas e Gestão (SimRPG) e o Jogo de Relacionamentos Estratégicos (JRE). Constatou-se que o SimRPG, dinamizado pelo JRE, contribuiu para a prática de conceitos de gestão e de Relações Públicas, valorizando seu papel estratégico e tornando tangíveis os resultados dos relacionamentos da organização com seus públicos. Concluiu-se que, além de uma inovação para a educação das Relações Públicas, o simulador e o jogo favoreceram a autonomia e a criatividade docente e discente, contribuindo na formação teórico-prática dos sujeitos envolvidos no processo de ensino-aprendizagem.

Palavras-chave: Relações Públicas. EnsinoAprendizagem. Simulador Organizacional.

\section{Abstract}

Didactic initiatives that articulate theory and practice, value the student's protagonism and integrate different types of contents in a dynamic, digital and interdisciplinary context are still scarce in Higher Education. In fostering create and use of active methodologies in Public Relations courses, this text presents some results of multi-methods research of doctorate degree in which the Simulator of Public Relations and Management (SimRPG) and Strategic Relationships Game (JRE). It was verified that the SimRPG, dynamized by the JRE, contributed to the practice of management concepts and Public Relations, valuing its strategic role and making tangible the results of the relationships of the organization with its public. It was concluded that, in addition to an innovation for Public Relations education, the simulator and the game favored the autonomy and creativity of teachers and students, contributing to the theoretical and practical training of the subjects involved in the teaching-learning process.

Keywords: Public Relations. Teaching-Learning. Organizational simulator.

\section{Introdução}

Iniciativas didáticas que articulem teoria e prática, valorizem o protagonismo do estudante e integrem diferentes conteúdos em um contexto dinâmico, digital e interdisciplinar ainda são escassas na Educação Superior. Foi especialmente a partir de 1996, com o advento da atual Lei de Diretrizes e Bases da Educação Nacional e a substituição da estrutura do Currículo Mínimo pelas Diretrizes Curriculares Nacionais que se passou a incentivar a articulação do saber acadêmico com a prática profissional nos cursos de graduação. Passou-se ainda a estimular a concepção de currículos que promovam a "progressiva autonomia profissional e intelectual do aluno, apto a superar os 
desafios de renovadas condições de exercício profissional e de produção de conhecimento e de domínio de tecnologias" (CNE/CES, 2003, p. 6).

Desde então, políticas públicas voltadas para a expansão e controle da qualidade da Educação Superior têm sido implantadas no Brasil. São exemplos destas ações: a) o Exame Nacional do Ensino Médio (Enem); b) a criação de cursos de graduação na modalidade a distância; c) a ampliação da oferta de cursos tecnológicos; d) a concepção de programas de bolsa como o Programa Universidade para Todos (ProUni) e o Financiamento Estudantil (Fies) e ainda; e) a criação do Sistema Nacional de Avaliação da Educação Superior (Sinaes). Em 20 anos (1996 a 2016), o número de IES passou de 922 para 2.407, o número de ingressantes aumentou em $481 \%$ e houve um acréscimo de $331 \%$ no número de matrículas e de $360 \%$ no número de concluintes (INEP, 1996 2016).

Embora existam visíveis avanços quantitativos, ainda é preciso superar inúmeras carências qualitativas, dentre as quais se destacam a adequada formação discente, a qualificação do corpo docente, a inclusão social e o estímulo à pesquisa científica e tecnológica. Na oficina de trabalho "Desafios e Perspectivas da Educação Superior Brasileira para a Próxima Década", realizada em evento preparatório para elaboração do Plano Nacional de Educação, tais pontos foram destacados. Nesta ocasião, ressaltou-se a falta da inserção qualificada das novas Tecnologias de Informação e de Comunicação (TIC) nas práticas educativas. Além disso, o debate contemplou a urgente necessidade de formação didática dos docentes visando repensar as metodologias educacionais numa perspectiva contextualizada e de acordo com o perfil dos novos estudantes (SPELLER; ROBL; MENEGHEL, 2012).

Considerando as metas estabelecidas para a Educação Superior no Plano Nacional de Educação (2014 - 2024), o Sindicato das Mantenedoras do Ensino Superior (2017) promoveu discussões com acadêmicos e especialistas e produziu um documento com diretrizes para orientar o Sistema de Ensino Superior do Brasil. Destacaram a inovação acadêmica, a formação de professores e a pesquisa, assim como a tecnologia e educação digital. Além disso, foi revelada a necessidade de o poder público estimular a criação de múltiplos modelos de educação que "promovam uma ação importante em matéria de conectividade, repositórios abertos de aprendizagem virtual, simuladores e formação de docentes em TIC e ensino a distância" (SEMESP, 2017, p.26).

Diversos autores (LIBÂNEO, 2003; MASETTO; 2003, 2010; PIMENTA; ANASTASIOU; 2010; ALMEIDA; 2012; GIL, 2013) alertam que a didática ainda é tema 
atual e relevante na Educação Superior no Brasil. Concordam que não basta dominar o conhecimento da área para saber ensinar, é necessário um conjunto de saberes e competências pedagógicas. Quanto à interdisciplinaridade, a partir de revisão conceitual, Thiesen (2008, p. 546) explica que esta deverá ser:

[...] articuladora do processo de ensino e de aprendizagem na medida em que se produzir como atitude (Fazenda, 1979), como modo de pensar (Morin, 2005), como pressuposto na organização curricular (Japiassu, 1976), como fundamento para as opções metodológicas do ensinar (Gadotti, 2004), ou ainda como elemento orientador na formação dos profissionais da educação.

Em resumo, é possível perceber que a Educação superior vêm sido pensada com insuficiente e descompassada no que tange às necessidades atuais do seu contexto. Estes autores defendem a persistência da necessidade da reflexão quanto ao significado e utilidade da tecnologia, justamente para que esta não se torne uma panaceia para os problemas sociais que interpenetram o campo educacional, nem se torne um fim em si mesmo, às expensas dos valores humanos, éticos e estéticos. Ainda assim, com o uso contextualizado dentro de uma finalidade mais ampla, a inovação e a educação digital podem se tornar ferramentas de grande utilidade para possibilitar uma formação ativa e reflexiva.

Diante dos fatores expostos, o texto apresenta alguns resultados de pesquisa multimétodos de doutorado que teve como objeto de estudo o processo ensinoaprendizagem nos cursos de graduação em Relações Públicas. No mencionado estudo, elaborou-se o modelo conceitual e matemático de um simulador organizacional, denominado Simulador de Relações Públicas e Gestão (SimRPG). Combinado ao Jogo de Relacionamentos Estratégicos (JRE), estratégia educacional desenvolvida para dinamizar o uso deste artefato didático, testou-se o protótipo deste simulador, criado em Excel 2010, com quatro turmas de graduação, totalizando 112 estudantes, na modalidade presencial.

Com o objetivo de fomentar a criação e o uso de metodologias ativas nos cursos de Relações Públicas, em especial, aquelas apoiadas em jogos e simuladores, apresentase uma breve revisão sobre seus benefícios e limitações, os aspectos gerais do modelo conceitual do SimRPG e o método e resultados da aplicação desta metodologia educacional em sala de aula. 


\section{Jogos e simuladores: benefícios e limitações}

O jogo como estratégia de ensino-aprendizagem é uma prática comum na Educação Básica e apenas recentemente utilizado na Educação Superior (GIL, 2013). Na perspectiva do game design, Schell (2008, p. 37) define o jogo como uma atividade de resolução de problemas encarada com uma atitude lúdica.

Como benefícios, Gil (2013) destaca que o uso dos jogos na educação proporciona amplo e imediato feedback; potencializa a sociabilidade; estimula a cooperação; ensina a trabalhar em ambientes competitivos; possibilita transferir informações de um contexto para outro; estimula a busca de informações; oferece desafios; engaja os participantes em busca de alcançar objetivos e adapta-se as necessidades de aprendizagem do indivíduo. Como limitações, ressalta a falta de preparo e experiência dos docentes na criação e uso de jogos; a necessidade de administrar emoções que surgem na vivência; o preconceito em relação a ludicidade da atividade; o risco dos jogos se tornarem atividades meramente recreativas e as dificuldades em relação a administração de tempo e recursos disponíveis.

Gil (2013) ainda diferencia jogos e simulações. Para o autor o "jogo é uma atividade espontânea realizada por mais de uma pessoa, regida por regras que determinam perda ou ganho. Já a simulação é caracterizada pela representação de situações reais num cenário simulado" (GIL, 2013, p.194). Desta forma, pode-se chamar de jogos simulados (GIL, 2013) aqueles que buscam reproduzir uma realidade, tais como os jogos de empresas (SAUAIA, 2013) ou simulações empresariais (BERNARD, 2006). É relevante destacar a diferença entre os jogos de interpretação de papéis (Role-Playing Games -RPGs) e os jogos de empresas (business games), apoiados no uso de simuladores organizacionais.

Para Alves (2015, p. 22), os RPGs "são jogos onde os participantes interpretam um personagem." Estão mais próximos das dinâmicas de grupo e das dramatizações. No ambiente acadêmico e de negócios lembram o estudo de caso. As soluções para o caso têm mais opções e a avaliação dos resultados depende de critérios adotados pelo mediador. Os jogos de empresas são mais robustos, pois os simuladores organizacionais, construídos a partir de modelos conceituais e matemáticos, conduzem o participante a converter decisões estratégicas em resultados objetivos.

O uso de jogos de empresas com apoio de simuladores organizacionais tem se mostrado interessante estratégia de aprendizagem experiencial, no qual os participantes aprendem com a prática conceitual (KEYS; WOLFE, 1990). Eles começaram a ser utilizados nas escolas de negócios norte-americanas a partir da década de 50, mas 
somente na década de 70 chegaram às escolas de Administração no Brasil. Desde então, são utilizados como estratégia de ensino-aprendizagem e tema de investigação científica.

Para Sauaia (2011, p.17), no jogo de empresas, "os participantes assumem diferentes papéis gerenciais, estabelecidos e apresentados previamente, definem as metas funcionais e as estratégias de sua organização simulada. Eles têm controle de suas ações e acompanham os resultados produzidos por suas decisões".

Segundo Bernard (2006, p. 85), o jogo de empresas é o "método de capacitação gerencial em que os participantes competem entre si através de empresas simuladas, tomando decisões que, processadas por um simulador, geram relatórios gerenciais para que um novo ciclo de análises e tomada de decisões seja realizado".

$\mathrm{Na}$ maioria das vezes, o jogo de empresas começa com a exposição oral do caso empresarial e das regras do simulador. Estas estão descritas em um manual do participante ou livro texto, cuja leitura é recomendada e a assimilação das regras pode ser verificada por meio de testes objetivos (SAUAIA, 2013). O Quadro 1 sintetiza os benefícios e limitações do uso de jogos de empresas nos cursos brasileiros:

Quadro 1 - Benefício e limitações do uso de jogos de empresas

\begin{tabular}{|c|c|}
\hline $\begin{array}{c}\text { Desenvolve conhecimentos, } \\
\text { habilidades e atitudes gerenciais e } \\
\text { empreendedoras (SAUAIA, 1990) }\end{array}$ & $\begin{array}{c}\text { Limitações } \\
\text { objetivos da simulação pão estiverem claros para os participantes } \\
\text { (BERNARD, 2006) }\end{array}$ \\
\hline $\begin{array}{c}\text { Oportuniza a aprendizagem } \\
\text { gerencial, cognitiva, cooperativa, } \\
\text { competitiva e afetiva (SAUAIA, } \\
\text { 1995) }\end{array}$ & $\begin{array}{c}\text { Custo elevado de aquisição e/ ou para o desenvolvimento da } \\
\text { ferramenta, não há disponibilidade de jogos abertos (BERNARD, } \\
\text { 2006, ARBEX et al., 2006, ROSAS; SAUAIA, 2006a) }\end{array}$ \\
\hline $\begin{array}{c}\text { Provê a união satisfatória entre } \\
\text { teoria e prática (ARBEX et al., } \\
\text { 2006) }\end{array}$ & $\begin{array}{c}\text { Pouco conhecimento da ferramenta pelo professor que aplica a } \\
\text { atividade (ARBEX } \text { et al., 2006) }\end{array}$ \\
\hline $\begin{array}{c}\text { Possibilita recuperar o caráter } \\
\text { sistêmico da organização } \\
\text { integrando as áreas funcionais } \\
\text { em um todo coerente (SAUAIA, } \\
\text { 2007) }\end{array}$ & $\begin{array}{c}\text { Falta de professores treinados com conhecimento teórico e prático } \\
\text { para conduzir as atividades, a atividade requer mais dedicação do } \\
\text { docente (ROSAS; SAUAIA, 2006a) }\end{array}$ \\
\hline $\begin{array}{c}\text { Proporciona o aprendizado em um } \\
\text { ambiente que mescla competição } \\
\text { e cooperação (ARBEX et al., } \\
\text { 2006) }\end{array}$ & $\begin{array}{c}\text { Deficiências na ferramenta para contemplar as necessidades de } \\
\text { simulação do professor (ARBEX et al., 2006) }\end{array}$ \\
\hline $\begin{array}{c}\text { Proporciona a } \\
\text { interdisciplinaridade (ARBEX et } \\
\text { al., 2006) }\end{array}$ & $\begin{array}{c}\text { Falta de infraestrutura da IES (laboratórios de informática) e } \\
\text { andamento da atividade (ARBEX et al., 2006, ROSAS; SAUAIA, } \\
\text { 2006a) }\end{array}$ \\
\hline
\end{tabular}

Fonte: elaboração própria 
Conforme Quadro 1, pode-se afirmar que os benefícios e limitações dos jogos de empresas devem ser analisados pelo professor, coordenador do curso ou direção da IES, quando se decidir pela sua utilização. Recomenda-se potencializar as qualidades e reduzir as barreiras para o adequado uso educacional desta estratégia de ensino-aprendizagem. $\mathrm{O}$ jogo de empresas ou simulação gerencial, por seus aspectos educacionais, é um exemplo de serious games, ou seja, um processo ensino-aprendizagem que permite ao estudante identificar conflitos organizacionais e testar seus conhecimentos de forma prática sob condições de incerteza (SAUAIA, 2013). Tem como suporte didático os simuladores organizacionais e acontece por meio da interação entre os participantes e a mediação docente. Pode ter características de jogos de interpretação de papéis, pois os participantes assumem papéis gerenciais. Além disso, permite que eles tenham contato imediato com as consequências de suas ações. Por isso, os jogos de empresas, bastante utilizados pelas escolas de negócios na formação e treinamento de gestores, são enfatizados neste estudo.

Destaca-se que, diante da busca operacional por resultados práticos ou financeiros, os jogos utilizados na área empresarial, pelos seus próprios fins, podem se tornar ferramentas que, em vez de educar, apenas formam técnicos experientes. Neste sentido, compatibilizar o desenvolvimento da reflexão junto à expertise técnica é um desafio para os avanços nesta área.

\section{SimRPG e JRE: características e uso educacional}

Em uma varredura em sites e textos sobre simuladores organizacionais comercializados e utilizados por empresas e grupos de pesquisa brasileiros, tais como SimuLab, Bernard, Simulare, GI Micro e OGG, a função de Relações Públicas não foi identificada. Na maioria deles, as decisões de comunicação estão atreladas à função de marketing e publicidade e propaganda. Nesta perspectiva, as Relações Públicas aparecem como uma atividade operacional e ferramenta de marketing e não como uma função organizacional estratégica como defendem autores da área (GRUNIG; HUNT, 1984; SIMÕES, 1995; KIM, 2001; KUNSCH, 2003).

Desta forma, o Simulador de Relações Públicas e Gestão (SimRPG) foi criado com o objetivo de apoiar simulações gerenciais, nas quais os participantes praticam conceitos de Relações Públicas e Gestão. A simulação gerencial para o uso do SimRPG foi denominada de Jogo de Relacionamentos Estratégicos (JRE). A sigla RPG, abreviação de Role Playing Game também remete as características do jogo de interpretação de papéis, 
uma vez que os participantes assumem funções gerenciais e lidam com as incertezas presentes no jogo.

Cabe destacar que a ferramenta foi desenvolvida para: 1) dar apoio à aprendizagem vivencial, gerencial, interdisciplinar e contextual; 2) promover a adequada articulação entre teoria e prática comunicacional e organizacional e 3) instrumentalizar docentes para o uso de metodologias ativas de ensino-aprendizagem.

O cenário ou caso empresarial (SAUAIA, 2013) descreve um mercado de empresas do setor de tecnologia. O principal produto comercializado são "computadores portáteis" vendidos no mercado doméstico especialmente para o setor varejista. A estrutura de mercado representa um oligopólio. Caracteriza-se pelo número reduzido de empresas vendedoras, um número elevado de compradores, a existência de diferenciação dos produtos e assimetria de informações disponíveis entre os competidores (ROSAS; SAUAIA, 2006b).

São empresas vulneráveis às condições do contexto do país. Os indicadores macroeconômicos presentes no SimRPG são o IGP (Índice Geral de Preços) e o IVS (Índice de Variação Sazonal). O primeiro indica a inflação/ deflação do período, influencia no poder de compra da moeda e impacta nos custos das empresas. O segundo indica períodos de maior ou menor demanda no mercado de acordo com eventos ou datas comemorativas e impacta nas vendas das empresas.

Os incidentes críticos ou eventos aleatórios dinamizam o cenário. São acontecimentos políticos, legais, sociais, culturais, entre outros que podem ser inseridos pelo docente ou surgir entre os participantes durante a vivência. Poderá haver momentos de competição e de cooperação como afirma Sauaia (2013). Por exemplo, o docente pode inserir um incidente crítico no qual o protesto de um grupo ativista contra o descarte inadequado de lixo eletrônico acarrete determinado ônus para as empresas que atuam no setor de tecnologia. O impacto do evento dependerá do tipo de relacionamento que a empresa tem com este público e/ou dos investimentos e ações de responsabilidade que elas realizam. Os incidentes críticos também permitem a articulação da ética com as finalidades econômicas das empresas, pois os estudantes podem, a partir de sua criatividade e reflexão, propor soluções inovadoras e avaliar os melhores meios para conciliar ganhos financeiros, valores morais e os relacionamentos com os diversos públicos.

Tais condições exigem das organizações operantes uma atuação sustentável e a construção e manutenção de relacionamentos estratégicos com seus públicos. No SimRPG, os públicos diretamente envolvidos são: consumidores, fornecedores, funcionários, 
acionistas, governo, mídia e comunidade. Embora outros públicos não estejam explicitados no SimRPG, eles podem ser explorados durante o JRE. O docente pode ainda solicitar ao projetista que determinado público seja incorporado à ferramenta de acordo com suas necessidades didáticas. No exemplo anterior, o tipo de relacionamento com a comunidade poderia balizar o impacto do protesto com os ativistas, pois este evento pode interferir no apoio da comunidade às práticas da empresa. Caso queira amenizar o efeito do incidente crítico, os estudantes "gestores" podem ser convidados a propor uma ação de comunicação com o público envolvido, conforme desafio apresentado. Assim, o docente pode explorar conceitos e teorias de Relações Públicas, tais como classificação e análise de públicos, modelos de comunicação, opinião pública, responsabilidade empresarial, mensuração de resultados entre outros.

No SimRPG, são dois os indicadores de sucesso da organização: o ROE (Return On Equity) e o IRP (Índice de Reputação). O primeiro (ROE) mede a capacidade da empresa em gerar valor financeiro utilizando os seus próprios recursos. Relaciona o Lucro Líquido obtido no decorrer dos períodos com o Patrimônio Líquido da empresa. O segundo (IRP) afere a qualidade dos relacionamentos e a percepção dos públicos em relação às práticas gerenciais da organização. O IRR (Indicador de Rentabilidade e Reputação) relaciona o ROE e o IRP e indica o desempenho geral da empresa no mercado. As funções gerenciais representadas no JRE e as principais variáveis presentes no SimRPG podem ser observadas no Quadro 2:

Quadro 2 - Funções gerenciais, responsabilidade e variáveis relacionadas

\begin{tabular}{|c|c|c|}
\hline Função gerencial & Responsabilidade no JRE & $\begin{array}{c}\text { Principais variáveis } \\
\text { no SimRPG }\end{array}$ \\
\hline Diretor Geral & $\begin{array}{c}\text { Responsável pelo planejamento estratégico da } \\
\text { empresa, liderança e articulação das demais } \\
\text { diretorias. }\end{array}$ & IVS e IGP \\
\hline Diretor de Marketing & $\begin{array}{c}\text { Responsável pelo gerenciamento da demanda e } \\
\text { do composto mercadológico. }\end{array}$ & $\begin{array}{c}\text { Preço*, Marketing* e } \\
\text { P\&D* }\end{array}$ \\
\hline $\begin{array}{c}\text { Diretor de Produção } \\
\text { Responsável pelo gerenciamento da produção. }\end{array}$ & $\begin{array}{c}\text { Volume de produção*, } \\
\text { Matéria-prima*, } \\
\text { Fábrica*, Estoques }\end{array}$ \\
\hline $\begin{array}{c}\text { Diretor de Recursos } \\
\text { Humanos }\end{array}$ & $\begin{array}{c}\text { Responsável pelo gerenciamento das pessoas } \\
\text { (selecionar, integrar, treinar, manter e avaliar) }\end{array}$ & $\begin{array}{c}\text { Mão-de-obra* } \\
\text { Públicas }\end{array}$ \\
$\begin{array}{c}\text { Responsável pelo gerenciamento dos } \\
\text { relacionamentos com os públicos e da reputação } \\
\text { da organização. }\end{array}$ & $\begin{array}{c}\text { Relacionamento com } \\
\text { funcionários*e demais } \\
\text { públicos, Ações de } \\
\text { Responsabilidade* e } \\
\text { Serviço Agregado ao } \\
\text { Consumidor* }\end{array}$ \\
\hline
\end{tabular}




\begin{tabular}{|c|c|c|}
\hline \multirow{2}{*}{ Diretor de Finanças } & $\begin{array}{c}\text { Imposto de Renda, } \\
\text { Dividendos, Despesas } \\
\text { financeiras, Despesas } \\
\text { Responsável pelo gerenciamento do caixa, } \\
\text { investimentos, controle da rentabilidade. } \\
\text { administrativas, Outros } \\
\text { gastos/ receitas**, } \\
\text { Depreciação, } \\
\text { Manutenção. }\end{array}$ \\
\hline
\end{tabular}

*Variáveis de decisão no SimRPG.

**Variável disponível no formulário de decisão cujos valores dependem de incidentes críticos/ negociações que possam surgir durante a vivência.

Fonte: elaboração própria

No Quadro 2 estão as principais funções, reponsabilidades e variáveis do SimRPG. São seis funções gerenciais e dez variáveis de decisões (*). As demais variáveis são computadas pelo sistema e devem ser monitoras pelos gestores. Embora as responsabilidades estejam segmentadas por funções, algumas áreas tais como Relações Públicas e Recursos Humanos compartilham atividades e decisões, neste caso, a decisão de relacionamento com os funcionários. O diálogo, a interdependência entre as áreas funcionais e a recuperação do caráter sistêmico da organização são aprendizagens estimuladas pela vivência.

Além disso, o JRE pode e deve ser enriquecido com atividades didáticas que complementem o sentido das variáveis explícitas no SimRPG. A equipe de gestores (estudantes) é convidada a produzir um plano estratégico para a empresa no qual o Diretor Geral é responsável pela sua estruturação, implementação e controle. Quando novos estudantes são introduzidos nas equipes, os diretores de Recursos Humanos, por exemplo, podem ser convidados a realizar o processo de seleção e integração do novo membro na empresa. As possibilidades didáticas são amplas uma vez que a vivência permite reproduzir, ainda que de forma simplificada, o mundo dos negócios (KEYS, 2010).

Com o objetivo de controlar a parametrização utilizada foram estabelecidas faixas mínimas e máximas para as variáveis de decisões disponíveis no SimRPG. No Quadro 3, a sua classificação de acordo com a literatura especializada: 
Quadro 3 - Classificação do SimRPG

\begin{tabular}{|c|c|c|}
\hline & Classificação & Descrição \\
\hline Abrangência & Geral & Representa 06 áreas funcionais da empresa. \\
\hline Complexidade & Simples & 10 variáveis de decisões. \\
\hline Interatividade & Interativo & $\begin{array}{l}\text { As decisões de uma organização afetam o mer- } \\
\text { cado e as decisões das demais organizações. }\end{array}$ \\
\hline $\begin{array}{c}\text { Comportamento das } \\
\text { variáveis }\end{array}$ & Determinístico & $\begin{array}{l}\text { As decisões são processadas a partir de mode- } \\
\text { los matemáticos. } \\
\text { A parametrização é dada pelo projetista e/ou } \\
\text { docente. }\end{array}$ \\
\hline Informatização & Computacional & Projetado em Excel 2010. \\
\hline Tomada de decisão & Físico/ eletrônico & $\begin{array}{l}\text { O formulário de decisão é físico. } \\
\text { Planilha de Apoio as Decisões (PAD) é ele- } \\
\text { trônica. }\end{array}$ \\
\hline
\end{tabular}

Fonte: baseado em Keys e Wolfe, 1990 e Bernard, 2006.

No Quadro 3, observa-se as principais características do SimRPG. O modelo matemático é determinístico, pois a partir das mesmas decisões dos jogadores, o artefato produz os mesmos resultados. No entanto, cenário e resultados são influenciados por fenômenos humanos e aleatórios, uma vez que o jogo é estratégico, interativo e acontece sob condições de incerteza. Em relação ao nível de informatização, a princípio, o SimRPG foi projetado em dois módulos de Excel 2010:

1. Módulo do professor: contém o gerenciador (processamento das decisões), dados do cenário (parametrização do caso empresarial), relatórios gerenciais do mercado (resultados de todos competidores) e relatórios gerenciais da empresa (resultados de cada organização). Estas planilhas estão interligadas. O gerenciador é calibrado com os dados do cenário. Após o processamento das decisões, o gerenciador produz os resultados que vão alimentar os relatórios gerenciais das empresas e do mercado. Estruturado em três subsistemas interligados (demanda, oferta e relacionamentos), o SimRPG foi desenvolvido com base nos modelos matemático e econômico de Gold e Pray (1983, 1984, 1990, GOLD, 2005). Já a lógica e as equações utilizadas para a inclusão do valor da reputação da organização foram baseadas em Cannon e Schwaiger (2004, 2005a, 2005b). Apoiou-se ainda nos estudos de Sauaia (2013) para enriquecer 
o referencial conceitual sobre simuladores organizacionais, jogo de empresas e economia e estratégia das organizações.

2. Módulo do estudante: contém uma Planilha de Apoio as Decisões (PAD) na qual o participante pode testar suas decisões de forma dinâmica. Está estruturado em três blocos verticais (situação da rodada/ decisões gerenciais/ situação projetada) e quatro blocos horizontais (decisões de demanda/ decisões de oferta/ decisões de relacionamentos/ informações financeiras). Para os resultados projetados, a PAD utiliza como parâmetros três possíveis cenários (otimista, conservador e pessimista) permitindo que o participante teste diferentes tipos de estratégias. Inclui ainda uma planilha de inputs dos resultados de cada rodada que serve para atualizar a PAD. O modelo desenvolvido integra conceitos não econômicos (valores intangíveis) e conceitos econômicos (valores tangíveis). Assim, os relacionamentos construídos com os diferentes públicos podem resultar em ônus ou bônus para as organizações e devem ser explorados de forma qualitativa e quantitativa pelo docente.

O infográfico na Figura 1 ilustra a dinâmica do JRE com o uso do SimRPG:

Figura 1 - Dinâmica do JRE com o uso do SimRPG

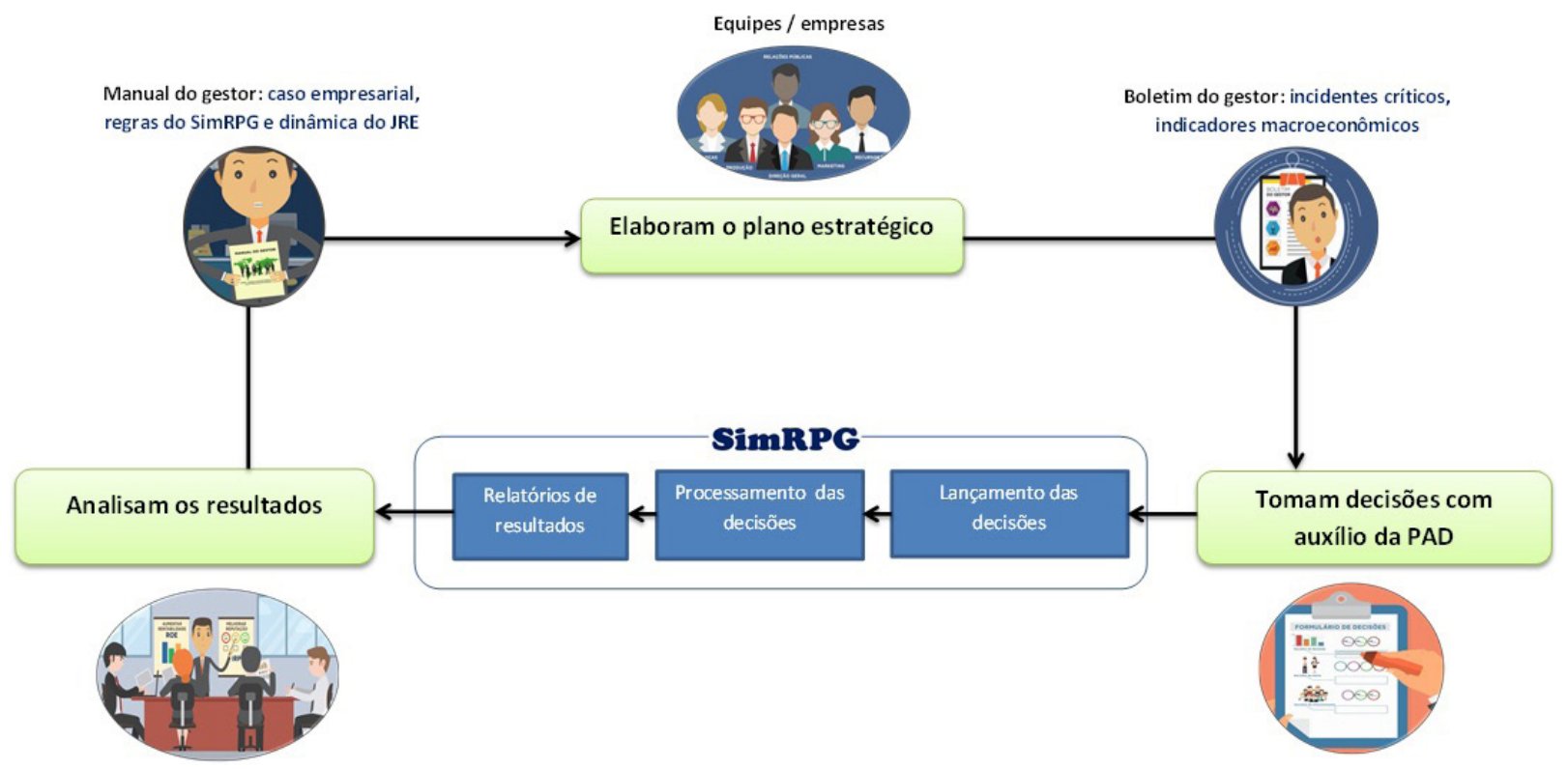

Fonte: elaboração própria (imagens do vídeo tutorial criado para a vivência)

Na Figura 1, observa-se que o Simulador de Relações Públicas e Gestão (SimRPG) é o artefato didático responsável pelo lançamento e processamento das decisões e pela 
produção dos relatórios com os resultados de cada empresa e do mercado. Tal artefato serve de apoio para a vivência educacional que é o Jogo de Relacionamentos Estratégicos (JRE). Aos participantes são apresentados o caso empresarial e as regras do simulador por meio de materiais didáticos desenvolvidos pelo projetista da atividade ou docente. Por meio do boletim do gestor, ou seja, material informativo distribuído para os participantes no início de cada rodada, o professor pode dinamizar o cenário inserindo incidentes críticos ou atividades que desafiem os estudantes a realizar pesquisas complementares, interagir entre as equipes ou ainda produzir e aplicar projetos as suas empresas simuladas.

\section{Aulas com o SimRPG e o JRE: metodologia e resultados}

Com o objetivo de verificar a aceitação e a usabilidade do SimRPG foram realizados testes com quatro turmas de graduação do curso de graduação em Relações Públicas, envolvendo 112 estudantes de uma universidade pública estadual, nos anos de 2016 e 2017. O planejamento curricular seguiu os objetivos educacionais gerais que consistiram principalmente em recuperar o caráter sistêmico e dinâmico da organização e levar os estudantes a praticar conceitos de gestão e Relações Públicas. Para cada turma, as atividades foram estruturadas de acordo com os objetivos específicos e o conteúdo programático das aulas. Dos testes de 2016 para os realizados em 2017, os materiais didáticos (plano estratégico, formulário de decisão, boletim do gestor, ficha de análise de resultados e template de proposta de ação para incidente crítico) foram aprimorados e adaptados.

Dada a finalidade de verificar a aceitação e a usabilidade do artefato e obter dados para aprimorá-lo, na avaliação, focalizou-se a percepção dos estudantes sobre o SimRPG e o JRE e na sua autoavaliação da experiência. Aplicou-se um questionário baseado no modelo de avaliação de reação para jogos educacionais, desenvolvido por Savi (2011). A escolha considerou a aplicabilidade do instrumento e a sua abrangência quanto aos aspectos relacionados à motivação, a experiência do usuário em jogos e a aprendizagem. Foram inseridas questões abertas para conhecer as impressões qualitativas dos participantes sobre a vivência. Estas perguntas incluíram, entre outras, pontos fortes e pontos fracos da atividade; principais aprendizagens e dificuldades percebidas e a sensação que ficou após a vivência. Os estudantes foram informados sobre os objetivos acadêmicos do estudo e da garantia do sigilo de suas identidades ao responderem os questionários. 
Do total de 112 estudantes, 93 (83\%) responderam o questionário, sendo 22 respondentes na Turma 1, 16 respondentes na Turma 2, 23 respondentes na Turma 3 e 32 respondentes na Turma 4. Para as 35 questões fechadas, realizou-se a tabulação de frequências por turma e do conjunto das quatro turmas. Foi utilizado o cálculo das médias das respostas por categorias e subcategorias, convertendo-se a escala de Likert pontuada de -2 até +2 em notas de 0 a 10 . Neste texto, focalizou-se apenas a análise das respostas às perguntas abertas sobre as aprendizagens percebidas pelos estudantes e sobre à satisfação geral e sensação em relação à experiência. Estas respostas foram processadas no software IRaMuTeQ, um programa de análise textual gratuito que permite fazer análises estatísticas sobre corpus textuais (CAMARGO; JUSTO, 2013) e interpretadas sob a perspectiva da Análise do Conteúdo. Segundo Bardin (2011, p. 48) "Enquanto esforço de interpretação, a análise de conteúdo oscila entre os dois polos do rigor da objetividade e da fecundidade da subjetividade". Em outras palavras, com o apoio de recursos de sistematização de dados qualitativos, buscou-se interpretar o conteúdo das respostas dos pesquisados, considerando as condições didáticas nas quais essas mensagens foram produzidas.

\section{Aprendizagens percebidas pelos estudantes}

Sobre as aprendizagens percebidas, estruturou-se um corpus formado por quatro textos constituído pelo conjunto de respostas qualitativas dos participantes de cada turma. Para as Turmas 1 e 2, tais textos versaram sobre os pontos fracos e pontos fortes do SimRPG e do JRE e para as Turmas 3 e 4, o conteúdo contemplou as principais aprendizagens e dificuldades percebidas durante a vivência. Com o auxílio do software IRaMuTeQ, realizou-se a análise de similitude que permitiu identificar as coocorrências entre as palavras, mostrar as conexões entre elas e a estrutura geral da representação da vivência para os participantes como ilustra a Figura 2: 
Figura 2 - Diagrama das aprendizagens no JRE

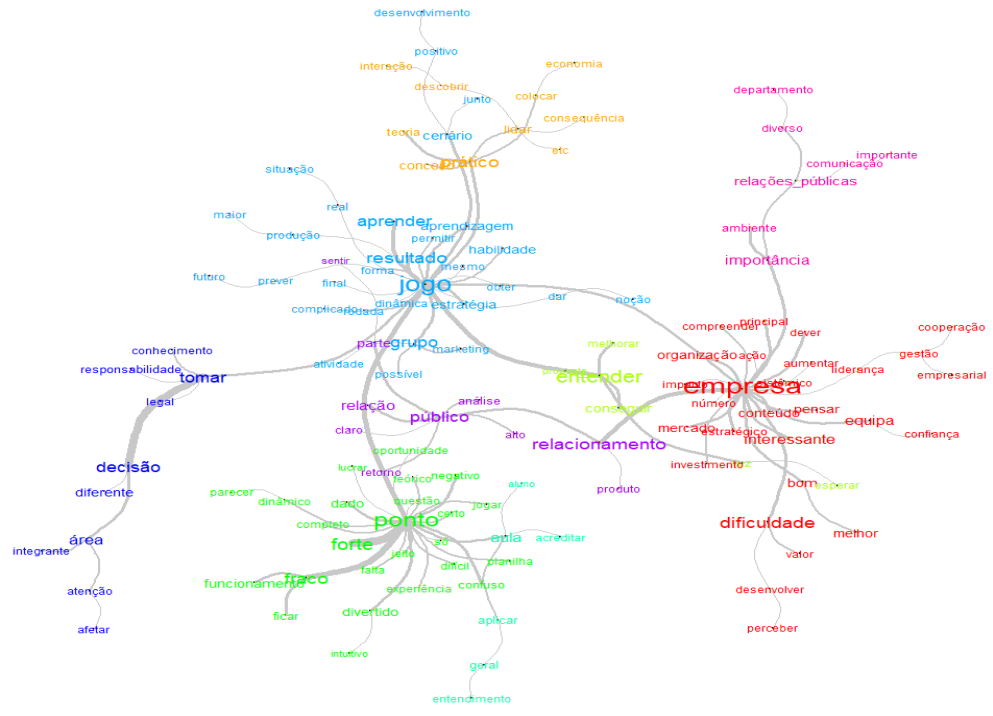

Fonte: desenvolvido em IRaMuTeQ 0.7, alpha 2, 2008 - 2014.

O diagrama da Figura 2 representa o resultado de análise de similitude com a identificação de comunidades de termos que se relacionam tais como "empresa" e “jogo". Na comunidade de termos "empresa" (vermelho), conectam-se os vocábulos "mercado", “estratégico", "gestão", “equipe”, “dificuldade", "liderança" entre outros. Outras comunidades de termos (rosa e lilás) ligam-se a esta com destaque para as palavras "importância", "relações públicas", "comunicação", “ambiente” em rosa e "relacionamento", “análise”, "público", "retorno" em lilás. Tais comunidades representam os aspectos da aprendizagem gerencial (SAUAIA, 1990, 1995, 2013) e o potencial da atividade para praticar conceitos de gestão e Relações Públicas percebidas pelos participantes.

Exemplos podem ser observados nas seguintes afirmações dos estudantes: "o jogo é um pouco complicado no início, no entanto, ajuda a entender o funcionamento de estratégias de relacionamento" (Turma 1); "o simulador trouxe e deixou muito claro a importância do papel estratégico gerencial de um Relações Públicas dentro da empresa sendo essencial a presença de tais profissionais na coalizão dominante” (Turma 3); " a experiência nos ensinou a trabalhar em equipe, a aplicar os conteúdos das aulas e pode nos mostrar como é a experiência do dia-a-dia não só de um Relações Públicas, mas da empresa no geral" (Turma 3); "percebi a complexidade do meio empresarial e a dificuldade de conciliar os diferentes departamentos" (Turma 3); "aprendi sobre a 
importância da comunicação para a estratégia da empresa e também sobre aspectos de liderança e gestão" (Turma 4).

O conteúdo dos discursos revelou que o SimRPG e o JRE aproximaram as áreas de Relações Públicas e Administração (TORRES, 2010), valorizando o papel estratégico de deste profissional (MORTARI; CASTRO, 2014), tal como defendem autores da área (GRUNIG; HUNT, 1984; SIMÕES, 1995; KIM, 20001; KUNSCH, 2003). Habilidades como liderança e conhecimentos em gestão, importantes na formação empreendedora (FERREIRA; ROSA, 2012), também foram destacadas pelos estudantes.

Na comunidade de termos "jogo” (azul celeste) encontram-se vocábulos como “aprender", "dinâmica", "estratégia", "resultado", "grupo" entre outras palavras que representam a contribuição desta estratégia educacional construtivista (SILVA, 2013) para a aprendizagem vivencial (SAUAIA, 2013) ou experiencial (KEYS; WOLFE, 1990) e desenvolvimento de habilidades interpessoais (BERNARD, 2006). Para um dos participantes "a dinâmica do jogo, interação entre as pessoas tornam o jogo interessante e construtivo" (Turma 1). Para outro "além de ser uma forma interativa e dinâmica de aprendizagem, o jogo permitiu que nós vivenciássemos uma verdadeira empresa, em seu lado bom e ruim" (Turma 3). Os depoimentos revelaram que, mesmo de forma simplificada, ao reproduzir o ambiente e o contexto organizacional (KEYS, 2010), tal estratégia aproximou os estudantes da realidade e oportunizou aprendizagem cooperativa, competitiva e afetiva (SAUAIA, 1995).

A esta comunidade conectam-se ainda as comunidades dos termos "ponto" (verde bandeira), "entender" (verde abacate), “tomar" (azul royal) e "prático" (amarelo). Na comunidade do termo "ponto", destacam-se "forte" e "fraco" e ainda uma subclasse de palavras ligadas pelo termo "aula" (turquesa). Como ponto fraco, o termo funcionamento representa um dos principais aspectos indicados pelos participantes a serem melhorados no simulador: "funcionamento um pouco complexo, demora para pegar o jeito" (Turma 1); "faltou um guia para explicar o funcionamento das planilhas" (Turma 2) e ainda "preciso entender melhor o funcionamento do mesmo" (Turma 3). O aprimoramento do Manual do Gestor, não utilizado na Turma 2, foi uma das melhorias que surgiu no decorrer do ano de 2016 para 2017. No entanto, é necessário avançar no design e funcionalidade da plataforma e enriquecer a atividade com reforçadores imediatos (SKINNER, 1972) aproveitando as potencialidades educacionais das novas tecnologias de informação e comunicação. 
Ao redor do termo "ponto", as palavras "experiência", "divertido", "confuso", "negativo", "dinâmico", representam aspectos mencionados tais como "um pouco confuso pra jogar com a pressa que estávamos" (Turma 2), "é divertido e diferente das aulas normais" (Turma 1) e "o único ponto negativo é que demorou um certo tempo para entendermos como funciona o jogo por conta da complexidade, mas depois fluiu normalmente" (Turma 1). Nesta comunidade de termos, os aspectos da diversão contribuem para motivar e engajar o estudante no processo de aprendizagem (GIL, 2013) e contrapõe-se a complexidade e abrangência do simulador que exigiu dos estudantes um olhar mais integrado e sistêmico do ambiente organizacional.

Ao termo "aula", as palavras "acreditar", "aplicar", "entendimento", "geral", o reconhecimento do caráter contextual da atividade, pode ser observado "uma primeira oportunidade de aplicar conceitos aprendidos em sala de aula, obtendo respostas satisfatórias e salientando a dificuldade de ter um panorama geral do negócio, em oposição a uma ideia anterior de que somente sua área especifica mereceria atenção" (Turma 3).

Interessante destacar neste depoimento que o estudante modifica sua compreensão das Relações Públicas como uma área isolada e restrita para um entendimento mais sistêmico da organização e contextual da função de Relações Públicas. Do mesmo modo, concilia conceitos aprendidos em sala de aula muitas vezes abstratos em demasia, com sua aplicação prática. Tal como recomendam as novas Diretrizes Curriculares Nacionais para os cursos de graduação em Relações Públicas (2013), a atividade mostrou-se potencialmente propícia para promover a visão sistêmica dos processos gerenciais e de comunicação e incentivar a análise conjuntural.

Ao vocábulo "entender" relacionam-se ainda palavras como "melhorar" e "conseguir" e mostram a percepção dos participantes em relação ao caráter desafiador e interdisciplinar (ARBEX et al., 2006) da atividade. Para um dos estudantes "a maior dificuldade foi entender o jogo, o que afeta, o que e como melhorar o desempenho e como interpretar os gráficos e os dados" (Turma 4) ou ainda "entender as falhas da primeira rodada para conseguir melhorar no futuro" (Turma 4). Para outro "a proposta do jogo é ótima, faz relação com os conteúdos de outras matérias como Teorias das Organizações" (Turma 3). Ainda, como recomendam as novas Diretrizes Curriculares Nacionais (2013), os estudantes reconheceram o potencial da atividade para articular diferentes disciplinas e foram desafiados na análise de dados qualitativos e quantitativos. 
Na comunidade "tomar", estão palavras como "decisão", "responsabilidade", "área", "diferente", "legal” e "conhecimento" o que indica que os participantes perceberam a atividade como propícia para assumir reponsabilidades e desenvolver habilidades de tomada de decisão (SAUAIA, 2013). Para um dos participantes, "é um jeito muito legal de simular a tomada de decisões em uma empresa" (Turma 1). Para outro, "a principal aprendizagem é tomar decisões em grupo que afetaria pessoas de fora aumentando a responsabilidade dessas decisões" (Turma 4). Ou ainda, “o jogo permite principalmente aprendizagem relacionada a tomada de decisões em momentos de incerteza (como será no mundo real). Permite ainda, trabalho em equipe e, a partir da dificuldade de lidar com valores e situações reais a aprendizagem de uma situação prática” (Turma 4).

Entre as habilidades e competências necessárias para a formação do profissional de Relações Públicas (DCNs, 2013), estão a tomada de decisão e a capacidade de integrar teoria e prática revelado no discurso apresentado. De tal forma, a integração entre os termos teoria e prática é enfatizada na comunidade do vocábulo "prático". Nesta, estão relacionadas palavras como "teoria", "conceito", "lidar", "consequência" e representa o potencial da atividade em integrar teoria e prática (ARBEX et al., 2006; SAUAIA, 2013). Segundo um dos participantes "pude ver na prática e em números as teorias estudadas" (Turma 1). Para outro, "o jogo ajudou a fazer uma ponte entre a teoria que estava sendo aprendida em sala com o mercado de trabalho, ainda que uma simulação foi possível ter uma imagem mais nítida da prática" (Turma 3). E, ressaltando o potencial da ferramenta de integrar valores tangíveis e intangíveis, valorizando o lado econômico e humano da organização, um dos participantes destacou "saber aplicar o conteúdo aprendido na prática de uma empresa que necessita ser bem posicionada no mercado, mas também precisa valorizar tudo que a constitui e torna ela uma empresa humana" (Turma 4).

Neste ponto, o SimRPG e o JRE contribuíram para a aprendizagem sobre os resultados efetivos das Relações Públicas no ambiente organizacional, mostrando aos estudantes o seu papel de profissional estratégico na construção dos relacionamentos com os públicos e na preservação da imagem e reputação das organizações (DCN's, 2013). De maneira geral, os participantes ficaram satisfeitos com a vivência, com uma média geral de satisfação de 8,5. Contudo, enquanto nas Turmas 1 e 2, a satisfação média foi de 8,6, verificou-se significativa diferença entre a média na satisfação na Turma 3 (média 9,6) e na Turma 4 (média 7,7).

Fatores contextuais como infraestrutura inadequada, tempo reduzido e número maior de estudantes e grupos a serem orientados na sala de aula no período noturno são 
fatores que podem ter contribuído para esta diferença (ARBEX et al., 2006; ROSAS; SAUAIA, 2006a). A experiência empresarial (BERNARD, 2006) de um dos monitores em uma das turmas também pode ter colaborado positivamente na vivência nesta classe. Neste sentido, é válida a constatação de Oliveira e Sauaia (2011) sobre a necessidade de disseminar a filosofia da aprendizagem vivencial no contexto da IES.

Uma vez que estratégias ativas demandam maior atenção individualizada dos professores aos grupos, o apoio pedagógico de professores tutores ou monitores é essencial em turmas com maior número de estudantes. Ademais, o desempenho do docente nunca é idêntico em todas as turmas, assim como o perfil e a receptividade dos estudantes a este tipo de atividade. Por isso, na mesma linha da educação construtivista, Dias, Sauaia e Yoshizaki (2013) recomendam a utilização de diversas estratégias de ensino para contemplar os diferentes estilos de aprendizagem.

\section{Sensação dos estudantes em relação à experiência}

Foi solicitado aos participantes que expressassem por meio de uma palavra ou frase a sensação que ficou ao final da vivência. Com o auxílio do software IRaMuTeQ, na Figura 3, observa-se a nuvem de palavras produzida a partir da frequência mínima de três ocorrências por termo computando os substantivos, adjetivos e verbos como formas ativas lematizadas:

Figura 3 - Nuvem de palavras - sensação ao final da vivência

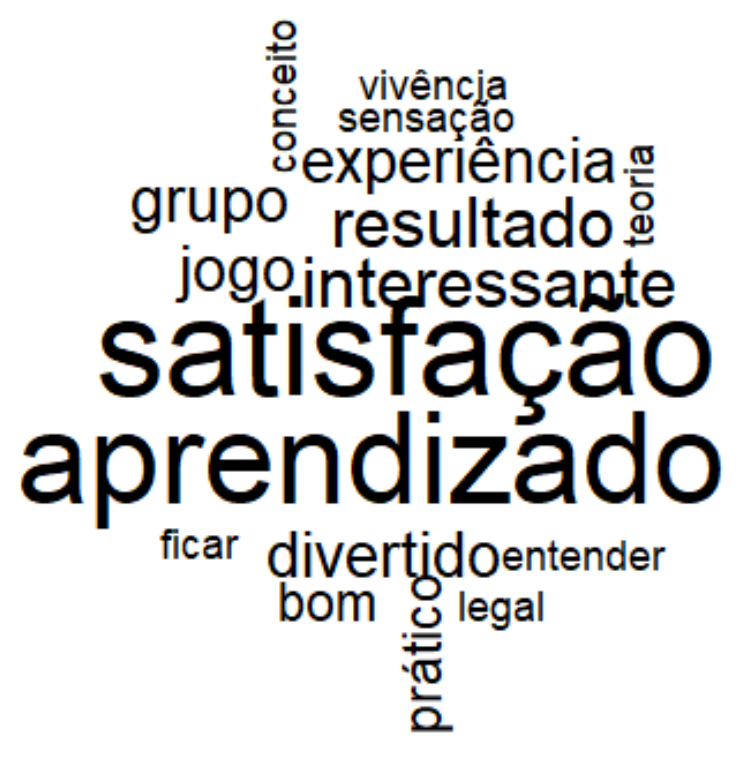

Fonte: desenvolvido em IRaMuTeQ 0.7, alpha 2, 2008 - 2014 com dados da pesquisa. 
Na Figura 3, observa-se que os termos com maior ocorrência foram "satisfação" e "aprendizado" confirmando, tal como verificou Sauaia (1995) em sua tese de doutorado, a capacidade dos jogos em combinar aprendizagem cognitiva e afetiva. Os termos "interessante", "resultado", "grupo", "experiência", "vivência" e "divertido" ressaltam ainda os benefícios da dinâmica para a aprendizagem cooperativa, competitiva e vivencial (SAUAIA, 1995; ARBEX et al., 2006.

Alguns comentários dos participantes ilustram os benefícios desta estratégia educacional: "realmente o jogo prende a atenção e te desafia a pensar estrategicamente a fim de atingir seus objetivos" (Turma 1); "satisfação por compreender o funcionamento das teorias e principalmente de fazer isso de forma interativa e divertida" (Turma 3) e "vontade de aprender e vivenciar mais o mundo corporativo" (Turma 4). Sendo assim, um ambiente construtivista baseado em jogos é aquele no qual o estudante tem papel ativo na aprendizagem, pois estimula a busca de informações e descoberta e engaja o estudante nas atividades educacionais (GIL, 2013).

"Prática" e "teoria" foram vocábulos que se destacaram: "a vivência foi muito positiva para a compreensão de conceitos teóricos na prática" (Turma 3) e, reconheceu outro estudante, "a prática é essencial para entender a teoria" (Turma 4). Necessário frisar que uma das finalidades da construção do SimRPG foi promover a adequada articulação entre teoria e prática comunicacional e organizacional como recomendam as novas DCNs (2013).

Foi também bastante significativo o surgimento de divergências entre estudantes e momentos de reflexão individual no processo concreto de tomada de decisões. No âmbito acadêmico das Relações Públicas, muitas vezes são discutidos princípios éticos que deveriam nortear os relacionamentos institucionais, tais como respeito à diversidade, transparência e boa fé na comunicação. Quando seguir princípios acarretou perdas em algum score do jogo, muitos estudantes optaram pelos maiores lucros, por exemplo ao se omitirem nas ações de responsabilidade social ou deixarem de investir condições de trabalho adequadas para os funcionários, criando maior rotatividade laboral. As consequências das decisões eram discutidas com a tutora, possibilitando que, mesmo que apenas em uma simulação, a ética deixasse de ser apenas falada para passar a ser vivenciada.

Embora com baixa ocorrência, identificou-se o termo "frustação", "confusão" e "falta de tempo" nas impressões finais dos participantes, especialmente nas Turmas 2 e 4: "iniciamos o jogo sem conhecer todas as funções, talvez por falta de tempo" (Turma 
2); "apesar da confusão em entender os investimento, houve aprendizado satisfatório" (Turma 4), "precisava de mais tempo" (Turma 4) e ainda "frustração, animação, competitividade" (Turma 4). Diminuir a complexidade das atividades para turmas com menor carga horária é um desafio que surge para os docentes em futuras aplicações. Desenvolver a habilidade de administrar o tempo e a atitude de lidar com erros e frustrações decorrentes de resultados negativos são importantes aprendizagens a serem trabalhadas para uma formação para o mercado de trabalho e para a vida. Segundo Piaget (1982), a construção das estruturas da inteligência é condição necessária, mas não suficiente, para a socialização, para o desenvolvimento moral e afetivo. Logo, a aprendizagem não é um processo apenas cognitivo, pois o indivíduo que toma contato com o ambiente pode desenvolver a afetividade e a moralidade. E, por isso, a relevância deste tipo de atividade para uma aprendizagem plena.

Interessante destacar que a atividade foi conduzida com turmas de primeiro ano de graduação, ou seja, que pouco ou nenhum contato tiveram com o mundo do trabalho e/ou com outras disciplinas específicas do curso. Um dos participantes afirmou: "acho que se jogássemos mais para frente do curso aproveitaríamos mais" (Turma 4). Na opinião de outro "para os alunos que gostam de aulas práticas é um bom exercício para primeiro ano" (Turma 2), ou ainda, como sugeriu um participante "acho até que poderia se tornar uma disciplina no curso" (Turma 3). Considera-se que este tipo de metodologia é propício para acolher e promover a aprendizagem entre pessoas de diferentes formações e níveis de conhecimento. De acordo com Sauaia (1995, 2013), tais ambientes podem ser desenhados como atividade complementar, disciplina curricular, oficina de treinamento, ambiente de iniciação científica e para produção de trabalho de conclusão de curso.

\section{Considerações finais}

Os resultados mostraram os benefícios educacionais do uso do simulador com o jogo para promover aprendizado e satisfação e articular teoria e prática. Além disso, a ferramenta demonstrou-se propícia para a aprendizagem de conceitos de gestão e de Relações Públicas, podendo seu uso ser adaptado a diferentes contextos interdisciplinares de formação, tais como para o empreendedorismo e para a atuação profissional e cidadã do comunicador no mundo organizacional. Cabe destacar que o uso de jogos configurou como uma das tendências globais na Educação Superior no relatório "New Media Consortium" (NMC, 2012 - 2017). 
Em recente revisão sistemática de literatura sobre os efeitos dos jogos e simulações na aprendizagem, Vlachopoulos e Makri (2017) analisaram 123 artigos científicos de uma base de 8.856 produzidos sobre o tema entre 2010 e 2016 . Verificaram um significativo aumento na produção a partir de 2012, confirmando a atualidade do tema. Os autores constataram que a maioria da produção concentra-se na Europa, Estados Unidos e Ásia, o que indica a necessidade do tema expandir-se para os países da América Latina e Brasil. Entre os gêneros identificados, tiveram destaque os jogos de simulação, tais como os jogos de empresas ou simulação empresarial, modalidade a qual pertence o SimRPG com o JRE. Foi na área de gestão de negócios e marketing que os estudos foram mais representativos, ou seja, campos do conhecimento de interface do protótipo desenvolvido. Os resultados da meta-análise realizada pelos mencionados autores indicaram o impacto positivo dos jogos e simulações na aprendizagem cognitiva, comportamental e afetiva. Resultados similares foram encontrados a partir dos testes realizados com os 112 estudantes no estudo conduzido no projeto de doutorado no qual se baseia este artigo.

Contudo, uma limitação refere-se aos simuladores organizacionais que, sendo sempre modelos simplificados, não dão conta de toda a dinâmica e complexa realidade. Embora o SimRPG seja propício à prática de conceitos de gestão e de Relações Públicas, úteis em qualquer tipo de organização, ele foi testado apenas na configuração do cenário de empresas privadas. Não se pode esquecer que este profissional deve estar apto a atuar nos três setores e, para a compreensão da lógica de um órgão público ou de uma organização do terceiro setor, é recomendável que outras configurações sejam testadas.

Em relação ao SimRPG, o projeto piloto foi conduzido com um protótipo desenvolvido em Excel 2010. É preciso considerar as restrições tecnológicas deste programa como, por exemplo, a incompatibilidade com versões anteriores e com outros sistemas operacionais que, em alguns momentos, dificultaram a visualização e funcionamento das planilhas. Em Excel 2010, a ferramenta é mais instável e suscetível a erros ocasionados por alterações de seus parâmetros. Neste ponto, o processo de auditoria de fórmulas e constantes tornou-se mais lento e impreciso. A estética e a dinamicidade da ferramenta também ficaram prejudicadas, sobretudo se comparadas às plataformas de última geração e ao design dos games que alguns jovens estudantes confrontaram o simulador utilizado.

Outra limitação refere-se à natureza dos dados utilizados. Priorizou-se analisar dados (quantitativos e qualitativos) relacionados à opinião dos pesquisados, portanto, vulneráveis aos vieses subjetivos, incluindo as emoções ocorridas durante a vivência e 
possível falta de sinceridade e imprecisão nas respostas. Dados de elevado teor pessoal priorizaram a percepção dos sujeitos sobre a realidade. Numa perspectiva construtivista, a interpretação é fundamental no processo de construção de conhecimento, porém, para avaliação do processo de aprendizagem, é necessário também entender e objetivar os conceitos, habilidades e atitudes desenvolvidas pelos estudantes na experiência educacional. Para este objetivo, seriam necessários estudos longitudinais mais amplos para acompanhar qualitativamente os efeitos do uso da metodologia.

Cabe destacar ainda que os testes com o SimRPG e JRE foram realizados apenas com turmas de graduação do primeiro ano de Relações Públicas de uma IES pública e com tempo reduzido de aplicação. Ou seja, é temerária qualquer generalização dos resultados sem o aprofundamento dos testes com outros grupos diferenciados.

Para avanços futuros, compartilha-se das recomendações de Vlachopoulos e Makri (2017), tais como pesquisas comparativas em ambientes laboratoriais de aprendizagem; avanços no design dos jogos para adequá-los a diferentes estilos de aprendizagem; alinhamento dos jogos ao currículo universitário; combinação de material e aprendizagem presencial e online; mobilização do corpo docente e engajamento do corpo discente como co-designers, ou seja, para contribuírem com ideias inovadoras que atendam as suas próprias necessidades de ensino-aprendizagem. Recomenda-se ainda o desenvolvimento do software do SimRPG com o intuito de viabilizar a difusão e disponibilização da ferramenta e suprir lacunas relacionadas à sua estética e funcionalidade. Tal desenvolvimento favorecerá a realização de testes mais robustos de parametrização das variáveis. Poderá ainda desfrutar de maneira mais efetiva dos benefícios das novas tecnologias de informação e comunicação, ou seja, será possível ampliar os estudos e aplicações sob a ótica do design didático digital.

Por fim, além de novas aplicações com o público-alvo fim (estudantes, profissionais e interessados em aprendizagem gerencial), também poderão ser realizadas atividades de sensibilização e mobilização com o público-alvo meio, ou seja, docentes, gestores, formadores e pessoas interessadas em utilizar e desenvolver este tipo de ferramenta e metodologia para promover a aprendizagem ativa. 


\section{Referências}

ALMEIDA, Maria Isabel. Formação do professor do ensino superior: desafios e políticas institucionais. São Paulo: Cortez, 2012.

ALVES, Paulo Vicente. Jogos e simulações de empresas. Rio de Janeiro: Alta Books, 2015.

ARBEX, Marco Aurélio et al. O uso dos Jogos de Empresas em Cursos de Graduação em Administração e seu valor pedagógico: um levantamento no Estado do Paraná. In: ENANPAD, 2006. Anais Eletrônicos [...]. Salvador, Bahia, EnANPAD, 23 a 27 de setembro/2006. Disponível em: http://www.anpad.org.br/enanpad/2006/dwn/enanpad2006-epqa-2470.pdf. Acesso em: 30 jun. 2016.

BARDIN, Lawrence. Análise de conteúdo. São Paulo: Edições 70, 2011.

BERNARD, Ricardo. O método de jogos de empresa/simulação gerencial. In: MARION, José Carlos; MARION, Arnaldo Luis Costa. Metodologias de ensino na área de negócios, São Paulo: Atlas, 2006. p. 83-114.

BRASIL. Parecer CNE/ CES 67/2003. Referencial para as Diretrizes Curriculares Nacionais - DCN dos Cursos de Graduação. Disponível em: http://portal.mec.gov.br/cne/arquivos/pdf/ CES0067.pdf. Acesso em: 3 jul. 2018.

BRASIL. Resolução CNE/ CES n ${ }^{\circ} 2$ de 27 de setembro de 2013. Institui as Diretrizes Curriculares Nacionais do curso de graduação em Relações Públicas. Disponível em: http://portal.mec.gov. br/index.php?option=com_docman\&view=download\&alias=14243-rces002-13\&Itemid=30192 . Acesso em: 08 out. 2015.

CAMARGO, Brigido Vizeu; JUSTO, Ana Maria. Tutorial para uso do software de análise textual IRAMUTEQ. Laboratório de Psicologia Social da Comunicação e Cognição (LACCOS), Universidade Federal de Santa Catarina, 2013. Disponível em: http://www.iramuteq.org/ documentation/fichiers/tutoriel-en-portugais. Acesso em: 12 jul. 2017.

CANNON, Hugh M.; SCHWAIGER, Manfred. Accounting for company reputation: variations on the Gold standard. Developments in Business Simulations and Experiential Learning, v. 31, p. 300-309, 2004. 
CANNON, Hugh M.; SCHWAIGER, Manfred. The role of company reputation in business simulations. Simulation \& Gaming, v. 36, n. 2, p.188-202, June 2005a.

CANNON, Hugh M.; SCHWAIGER, Manfred. An algorithm for incorporating company reputation into business simulations: variations on the Gold standard. Simulation \& Gaming, v. 36, n. 2, p. 219-237, June 2005b.

DIAS, George Paulus Pereira; SAUAIA, Antonio Carlos Aidar; YOSHIZAKI, Hugo Tsugunobu Yoshida. Estilos de aprendizagem Felder-Silverman e o aprendizado com jogos de empresa. RAE, v. 53, p. 469-484, 2013.

FERREIRA, Joana Garcia; ROSA, Rosane. A identidade empreendedora dos cursos de Relações Públicas da região sul do Brasil. Revista Razón Y Palabra, v. 17, n. 79, mayo - julio, 2012. s/p. Disponível em: http://www.razonypalabra.org.mx/N/N79/V79/02_GarciaRosa_V79.pdf. Acesso em: 30 jun. 2017.

GIL, Antonio Carlos. Didática do ensino superior. 1.ed. 8 reimpr. São Paulo: Atlas, 2013.

GOLD, Steven. System-dynamics-based modeling of business simulation algorithms. Simulation \& Gaming, v. 36, n. 2, p. 203-218, June 2005.

GOLD, Steven; PRAY, Thomas F. Modeling non-price factors in the demand functions of computerized business simulations. Developments in Business Simulations \& Experiential Exercises, v. 11, p. 240-243, 1984.

GOLD, Steven; PRAY, Thomas F. Simulating market and firm level demand - a robust demand system. Developments in Business Simulations \& Experiential Exercises, v. 10, p. 101-106, 1983.

GOLD, Steven; PRAY, Thomas F. Modeling demand in computerized business simulations. Guide to Business Gaming and Experiential Learning, p. 117-138, 1990.

GRUNIG, James E.; HUNT, Todd. Managing public relations. USA/ Belmont: Thomson Learning, 1984. 


\section{INSTITUTO NACIONAL DE ESTUDOS E PESQUISAS EDUCACIONAIS ANÍSIO} TEIXEIRA. Sinopse Estatística da Educação Superior (1996-2016). Disponível em: http:// portal.inep.gov.br/web/guest/sinopses-estatisticas-da-educacao-superior. Acesso em: 3 jul. 2018.

KEYS, Bernard. Entrevista 2010 - Bernie Keys: a experiência com simulação gerencial do fundador da ABSEL e o futuro da metodologia. In: Portal Bernard Simulação Gerencial 25 anos, 2010. Disponível em: http://bernard.com.br/entrevistas/entrevista-2010-bernie-keys/. Acesso em: 10 jul. 2017.

KEYS, Bernard; WOLFE, Joseph. The role of management games and in simulation in education and research. Journal of Management, v. 16, n. 2, p. 307-336, 1990.

KIM, Yungwook. Measuring the Economic Value of Public Relations, Journal of Public Relations Research, v. 13, n. 1, p. 3-26, 2011. DOI: 10.1207/S1532754XJPRR1301_2

KUNSCH, Margarida M. Krohling. Planejamento de Relações Públicas na Comunicação Integrada. Ed. rev. atual. e ampl. São Paulo: Summus, 2003.

LIBÂNEO, José Carlos. O ensino de graduação na universidade: a aula universitária. 2003. Disponível em: www.ucg.br/site_docente/edu/libaneo/pdf/ensino.pdf. Acesso em: 5 abr. 2014.

MASETTO, Marcos Tarciso. Competências pedagógicas do professor universitário. São Paulo: Summus, 2003.

MASETTO, Marcos Tarciso. Docência no ensino superior voltada para a aprendizagem faz a diferença. São Paulo: Universidade de São Paulo, Pró-reitoria de graduação. Cadernos de Pedagogia Universitária, n. 12, 2010. Disponível em: http://www.prpg.usp.br/attachments/ article/640/Caderno_12_PAE.pdf. Acesso em: 02 set. 2015.

NMC/CoSN Horizon Report: 2017 K-12 Edition. Disponível em: https://cdn.nmc.org/ media/2017-nmc-cosn-horizon-report-k12-EN.pdf. Acesso em: 10 jul. 2018.

MORTARI, Elisângela Carlosso Machado; CASTRO, Aline Eggres de. Relações Públicas como função estratégica: um caminho a ser traçado. Revista Matrizes, v. 8, n. 1, p.271 - 285, jan./jun. 2014. 
OLIVEIRA, Murilo Alvarenga; SAUAIA, Antonio Carlos Aidar. Impressão docente para aprendizagem vivencial: um estudo dos benefícios dos jogos de empresas. Revista Administração: Ensino e Pesquisa, Rio de Janeiro, v. 12, n. 3, p. 355-391, Jul./Ago./Set. 2011.

PIAGET, Jean. O nascimento da inteligência na criança. 4. ed. Rio de Janeiro: Zahar editores, 1982.

PIMENTA, Selma Garrido; ANASTASIOU, Léa das Graças Camargos. Docência no ensino superior. 4. ed. São Paulo: Cortez, 2010.

ROSAS, André Rosenfeld; SAUAIA, Antonio Carlos Aidar. Jogos de empresas na educação superior no Brasil: perspectivas para 2010. Enfoque: reflexão contábil, v. 25, n. 2, p. 72-85, set./ dez. 2006.

ROSAS, André Rosenfeld; SAUAIA, Antonio Carlos Aidar.Variáveis microeconômicas em simuladores para jogos de empresas: um estudo comparativo. Revista de Gestão da USP, São Paulo, v. 13, n. 3, jul./set. 2006b. p. 23-39.

SAUAIA, Antonio Carlos Aidar. Jogos de empresas: tecnologia e aplicação. Dissertação (Mestrado em Administração). Faculdade de Economia, Administração e Contabilidade, Universidade de São Paulo. São Paulo: USP, 1990.

SAUAIA, Antonio Carlos Aidar. Satisfação e aprendizagem em jogos de empresas: contribuições para a educação gerencial. Tese (Doutorado em Administração). Faculdade de Economia, Administração e Contabilidade da Universidade de São Paulo. São Paulo: USP, 1995.

SAUAIA, Antonio Carlos Aidar. Jogos de empresas na Educação Superior: o que são e para que servem. In: BOUZADA, Marco Aurélio. Jogando logística no Brasil. Curitiba: Editora CRV, 2011, p. 10-35.

SAUAIA, Antonio Carlos Aidar. Laboratório de Gestão: simulador organizacional, jogo de empresas e pesquisa aplicada. 3. ed. Manole: Barueri, São Paulo, 2013. 
SAUAIA, Antonio Carlos Aidar. Workshop em jogos de empresas: uma vivência para coordenadores, docentes e pesquisadores. In: ENCONTRO DE ENSINO E PESQUISA EM ADMINISTRAÇÃO E CONTABILIDADE. 1., 2007. Anais Eletrônicos [...]. EnEPQ, Recife, 21 a 23 de novembro de 2007. Disponível em: http://www.anpad.org.br/diversos/trabalhos/EnEPQ/ enepq_2007/ENEPQ175.pdf. Acesso em: 30 jun. 2016.

SAVI, Rafael. Avaliação de jogos voltados para a disseminação do conhecimento. Tese (Doutorado em Engenharia e Gestão do Conhecimento). Florianópolis, UFSC, SC, 2011. Disponível em: https://repositorio.ufsc.br/bitstream/handle/123456789/96046/299498. pdf?sequence. Acesso em: 18 ago. 2017.

SCHELL, Jesse. The art of game design. A book of lenses. United States, Morgan Kaufmann Publishers is an imprint of Elsevier, 2008.

SEMESP. Sindicato das Mantenedoras do Ensino Superior. Diretrizes de Política Pública para o Ensino Superior Brasileiro 2017. Disponível em: http://www.semesp.org.br/wp-content/ uploads/2017/09/Diretrizes-de-Poli\%CC\%81tica-08-08-.pdf. Acesso em: 03 jul. 2018.

SILVA, Marco Antônio. Laboratório de Gestão: jogo de empresas com pesquisa para a formação crítica em Administração. Tese (Doutorado em Administração). Faculdade de Economia, Administração e Contabilidade da USP, 2013.

SIMÕES, Roberto Porto. Relações Públicas: função política. 3. ed. rev. e ampl. São Paulo: Summus, 1995.

SKINNER, Burrhus Frederic. Tecnologia de ensino. São Paulo: Herder, Ed. Da universidade de São Paulo, 1972.

SPELLER, Paulo; ROBL, Fabiane; MENEGHEL, Stela Maria. Documento final: "Desafios e perspectivas da educação superior brasileira para a próxima década”. In: SPELLER, Paulo; ROBL, Fabiane; MENEGHEL, Stela Maria. Desafios e perspectivas da educação superior brasileira para a próxima década. Brasília: UNESCO, CNE, MEC, 2012. p. 155-162. Disponível em: http://unesdoc.unesco.org/images/0021/002189/218964POR.pdf. Acesso em: 03 jul. 2018.

THIESEN, Juares da Silva. A interdisciplinaridade como um movimento articulador no processo ensino-aprendizagem. Rev. Bras. Educ., Rio de Janeiro, v. 13, n. 39, p. 545-554, dez. 2008. 
TORRES, Desire Blum Menezes. As fronteiras entre os cursos de Relações Públicas e Administração de Empresas. Rev. Estud. Comun., Curitiba, v. 11, n.26, p. 211-216, set./dez. 2010.

VLACHOPOULOS, Dimitrios; MAKRI, Agoritsa. The effect of games and simulations on higher education: a systematic literature review. International Journal of Educational Technology in Higher Education, v. 14, p. 22, 2017. Disponível em: https://educationaltechnologyjournal. springeropen.com/articles/10.1186/s41239-017-0062-1. Acesso em: 10 jul. 2018.

1 Docente no curso de Relações Públicas da Universidade de Sorocaba (Uniso). É doutora em Ciências da Comunicação pela Escola de Comunicações e Artes da Universidade de São Paulo (ECA/ USP). Autora de "Entre os fios e o manto: tecendo a inclusão escolar" (2014) e coautora dos livros "Gestão Estratégica de Pessoas: obtendo resultados com a ISO 10015" (2013) e "A psicologia e o processo educativo" (2015). E-mail: anapiletti@hotmail.com

2 Servidor Público na Câmara Municipal de Sorocaba. É mestre em Educação pela Universidade de Sorocaba (Uniso), bacharel em Ciências Sociais pela Universidade de São Paulo (USP) e em Psicologia pela Universidade Paulista (Unip). É coautor do livro “A psicologia e o processo educativo” (2015). E-mail: luisgrohs@hotmail.com 